\section{Journal of Anatolian Environmental and Animal Sciences \\ (Anadolu Çevre ve Hayvancılık Bilimleri Dergisi) \\ Doi: https://doi.org/10.35229/jaes.596235}

\title{
Goji berry (Lycium barbarum L.) Meyvesinin Farklı Çözgenlerden Elde Edilen Ekstratlarının Toplam Fenolik İçerikleri ile Antioksidan ve Antimikrobiyal Aktivitelerinin Karşılaştırılması
}

\author{
Mehmet Soner ENGIN $\quad$ Selin KALKAN* Mustafa Remzi OTAĞ \\ Giresun Üniversitesi, Mühendislik Fakültesi, Gıda Mühendisliği Bölümü, Giresun, Türkiye Adresler \\ (DD: https://orcid.org/0000-0001-5954-5628, * *iD: https://orcid.org/0000-0002-4142-3152, (iD): https://orcid.org/0000-0001-5450-1546
}

Atıf yapmak için: Engin, M.S., Kalkan, S. \& Otă̆, M.R. (2019). Goji berry (Lycium barbarum L.) meyvesinin farklı çözgenlerden elde edilen ekstratlarının toplam fenolik içerikleri ile antioksidan ve antimikrobiyal aktivitelerinin karşılaştırılması. Anadolu Çev. ve Hay. Dergisi, 4(2), 359-365.

How to cite: Engin, M.S., Kalkan, S. \& Otağ, M.R. (2019. Comparison of total phenolic content, antioxidant and antimicrobial activities of goji berry fruit extracts from different solvents. Anatolian Env. and Anim. Sciences, 4(2), 359-365.

Öz: Bu çalışmada besleyici ve antioksidan özelliklere sahip bir "süper gıda" olarak kabul edilen Goji berry (Lycium barbarum L.) asetik asit+su ve etanol ektraktlarının toplam fenolik madde miktarı ile antioksidan ve antimikrobiyal aktiviteleri gibi biyoaktif özellikleri incelenmiştir. Farklı çözücüler kullanılarak hazırlanan ektratlarda en yüksek toplam fenolik madde içeriği $5148 \mu \mathrm{g}$ GAE/g ile etanol ektresinde tespit edilmiştir. Antioksidan aktivite sonuçlarına göre en yüksek DPPH inhibisyonu \%68,92 olarak asetik asit+su ektraktında belirlenmiştir. Disk difüzyon yöntemine göre ekstraktların antimikrobiyal özellikleri değerlendirildiğinde, test mikroorganizmalarından Staphylococcus aureus' a karş1 15.00 - $15.67 \mathrm{~mm}$ ve Listeria monocytogenes' e karş1 ise 14.33- $16.33 \mathrm{~mm}$ 'lik zon çapları ile güçlü bir antimikrobiyal etkiye sahip oldukları tespit edilmiştir.

Anahtar sözcükler: Lycium barbarum L., ekstraksiyon, biyoaktivite.

\section{Comparison of Total Phenolic Content, Antioxidant and Antimicrobial Activities of Goji berry Fruit Extracts from Different Solvents}

\footnotetext{
Abstract: In this study, acetic acid+water and ethanol extracts of Goji berry (Lycium barbarum L.) which is considered as super food with nutritious and antioxidant properties were investigated. The highest total phenolic content of the extracts prepared using different solvents was determined in ethanol with $5148 \mu \mathrm{g} \mathrm{GAE} / \mathrm{g}$. According to the results of antioxidant activity, the highest DPPH inhibition was determined as $68.92 \%$ in acetic acid+water extract. When the antimicrobial properties of the extracts were evaluated according to the disc diffusion method, it was found that they had a strong antimicrobial effect with zone diameters of $15.00-15.67 \mathrm{~mm}$ against Staphylococcus aureus and 14.33 $16.33 \mathrm{~mm}$ against Listeria monocytogenes.
} 


\section{GIRIȘ}

Goji berry (Lycium barbarum L.), şifalı özellikleri nedeniyle, geleneksel Çin tıbbında kullanılan önemli bitki türlerinden biridir. $\mathrm{Bu}$ bitki, Kuzeybatı Çin'de yetiştirilmektedir ve günümüzde Çin, Güneydoğu Asya ve birçok Avrupa ülkesinde günlük fonksiyonel gıda olarak kullanılmaktadır (Amagase \& Nance, 2008; Chang \& So, 2008). Lycium barbarum L. (goji) meyvesi, son derece avantajlı besleyici ve antioksidan özelliklere sahip bir "süper gıda" olarak kabul edilmesinden dolayı son birkaç yılda daha popüler hale gelmiştir. Meyvelerden hazırlanan konsantre özler ve infüzyonlar, yaşlanma karşıtı kullanılma, görme, böbrek ve karaciğer fonksiyon yararlarından dolayı pazarlanan çeşitli alkolsüz veya alkollü içeceklerde bileşen olarak kullanım geçmişine sahiptir. Ayrıca goji meyveleri çorba ve iz karışımları, pirinç lapasıyla tüketilir ve çok sayıda et ve sebze yemeğine eklenebilir (Yin \& Dang, 2008; Potterat, 2010). Ağustos-Ekim ayları arasında hasat edilen meyveler genellikle kurutulur, ancak aynı zamanda değerli bir sebze olarak taze tüketilebilirler (Potterat, 2010). Şekil 1 'de hasat öncesi olgunlaşmış goji meyveleri gösterilmiştir.

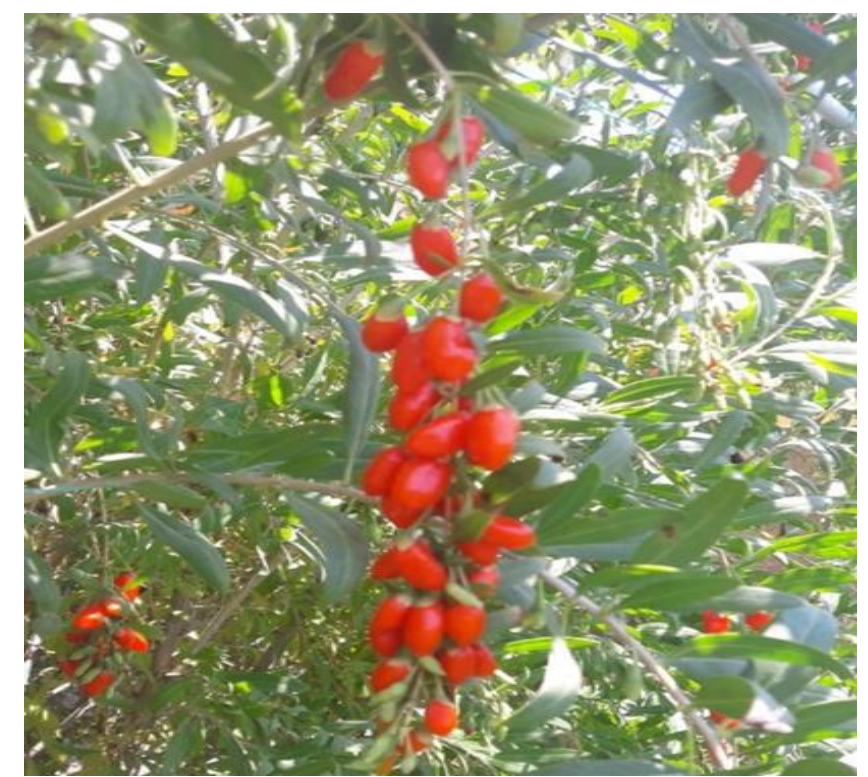

Şekil 1. Goji berry (Lycium barbarum L.) meyveleri.

Goji meyveleri veya kurt üzümü olarak da bilinen Lycium barbarum $L$. geleneksel Çin tıbbında iyi bilinen bir bitkidir. Lycium barbarum L. meyvesinde çeşitli kimyasal bileşenler bulunur. En önemli aktif bileşikler polifenoller, polisakaritler ve karotenoidlerdir. Kirmızımsı turuncu rengi, kurutulmuş meyvenin sadece $\% 0.03$ - 0.5 'ini oluşturan bir grup karotenoidden türetilir (Peng vd., 2005). Meyveler, antioksidan kapasiteye sahip, askorbik asidin doğal bir türevi olan 2-O- $\beta$-D-glikopiranosil-L-askorbik asit (Vitamin C) gibi besleyici ve tıbbi açıdan önemli bileşikler bakımından zengindir (Zhang vd., 2011). Bilimsel literatür, özellikle biyolojik olarak aktif organik bileşiklerin (fenoller ve flavonoidler) belirlenmesini gösteren, olumlu sağlık etkileri olan yiyeceklere (örneğin açaí, goji meyveleri veya chia tohumu) odaklanmaktadır. Lycium barbarum polisakaritleri (LBP'ler), goji meyvelerinin immünomodülasyon ve antikanser aktivitesinde etkilidirler (Gan vd., 2004). Goji meyveleri en güçlü antioksidanlardan biri zeaksantin diplamitattir ve güçlü antienflamatuar etkileri bulunmaktadır. Goji meyveleri genellikle kurutulmuş formda tüketilir. Şekilsel olarak kırmızı kuru üzüme benzeyen bir görünüme sahiptir (Manikandan vd., 2016; Gong \& Rubin, 2015). Çiğ taze meyvelerin $(100 \mathrm{~g})$ yaklaşık $4.49 \mathrm{~g}$ protein, $2.33 \mathrm{~g}$ toplam lipid, $9.12 \mathrm{~g}$ toplam karbonhidrat, $7.83 \mathrm{mg}$ karoten, $0.23 \mathrm{mg}$ tiamin, $0.33 \mathrm{mg}$ riboflamin ve $1.7 \mathrm{mg}$ niasin içerdiği bilinmektedir (Huang vd., 1999). Ayrıca, bakır, germanyum, demir, selenyum ve çinko dahil olmak üzere 21 iz mineral içerirler [Zhang vd., 2001; Sze vd., 2008). Goji meyveleri ayrıca esansiyel amino asitlerin tamamını içeren 18 amino asit bulundurmaktadır.

Goji berry'de bulunan flavonoidler (rutin, myricetin, quercetin, kaempferol) ve fenolik asitler (kafeik asit, klorojenik asit ve kumarik asit), Goji berry'nin antioksidan ve antimikrobiyal aktivite sergilenmesine neden olan ana bileşenlerdir (Amagase \& Farnsworth, 2011; Kulczyński \& Gramza-Michałowska, 2016). Özellikle, bu tür doğal antimikrobiyallerin etkilerinin belirlenmesinde, antimikrobiyal aktiviteye katılan biyoaktif moleküllerin tam rolü ve optimal konsantrasyonunun yanı sıra bu bileşikleri elde etmek için optimal ekstraksiyon işlemlerinin de ele alınması gereklidir (Skenderidis vd., 2019). Ekstraksiyon işleminde uygulanan çözücüler (örneğin; su, alkol) ve koşullar (örneğin; sıcaklık, zaman), biyoaktif bileşiklerin nihai bileşiminin ve dolayısıyla Goji meyvelerinin antimikrobiyal özelliklerinin belirlenmesi için çok önemlidir (Carvalho vd., 2016).

$\mathrm{Bu}$ çalışmada tıbbi olarak anti-oksidasyon, antiradyasyon (Qian vd., 2004), antikanser (Chao vd., 2006), hemopoiesis artırıcı (Hsu vd., 1999), yaşlanma karşıtı (Yu vd., 2005), antitümör aktivitesi ve sitoproteksiyon (Amagase \& Nance, 2008; Chang \& So, 2008) sergileyen goji meyvelerinin asetik asit ve etil alkol ekstratlarının toplam fenolik bileşiklerinin, antimikrobiyal ve antioksidan aktivitelerinin belirlenmesi amaçlanmıştır.

\section{MATERYAL VE METOT}

Materyal: Çalışmada kullanılan Goji berry (Lycium barbarum L.) meyveleri kurutulmuş olarak Samsun, Türkiye'den yerel bir aktardan temin edilmiştir. Çalışmada kullanılan Gram pozitif (Listeria monocytogenes ATCC 19115, Staphylococcus aureus (ATCC 25923), Bacillus cereus, Staphylococcus epidermis (ATCC 12228), Enterococcus faecalis (ATCC 29212)) ve Gram negatif (Escherichia coli Type 1, Vibrio parahaemolyticus (ATCC 17802), Salmonella typhimurium (ATCC 14028), Yersinia pseudotuberculosis (ATCC 911), Klebsiella pneumoniae (ATCC 700603), Proteus vulgaris (ATCC 13315)) bakteriler 
ile Aspergillus niger ve Candida albicans test mikroorganizmaları Giresun Üniversitesi Gıda Mühendisliği Bölümü kültür koleksiyonundan temin edilmiştir. Kültürlerin 0.5 McFarland skalası esas alınarak mililitresinde $1.5 \times 10^{6}$ $(\mathrm{KOB} / \mathrm{mL})$ hücre olacak şekilde bakteri ve maya-küf stok solüsyonları hazırlanmıştır (Noshada vd., 2018).

Goji meyvelerinin ektraksiyonu: 25 gr olarak tartılan kurutulmuş ve iyice ögütülmüş meyve örnekleri, içerisinde $98.5 \mathrm{~mL}$ saf su ve $1.5 \mathrm{~mL}$ asetik asit bulanan bir erlene aktarılarak G1A olarak isimlendirilmiştir. Etanol ektraksiyonu için $25 \mathrm{~g}$ kurutulmuş-ögütülmüş meyveler, 100 $\mathrm{mL}$ etanol içeren erlene aktarılarak G1E olarak isimlendirilmiştir. 24 saat boyunca, oda sıcaklığında çalkalamalı karıştırıcıda iyice karışmış olan numuneler filtre kâğıdından (Whatman filter paper No.1) geçirilerek süzülmüştür. Süzme işleminden sonra geriye kalan posalara çözgenler yeniden eklenip ikinci kez 24 saat karışmaya bırakılmıştır. Süzülen ekstrakt beherlere alınarak, analizlerde kullanılmak üzere buzdolabında $+4{ }^{\circ} \mathrm{C}$ 'de depolanmıştır (Engin vd., 2018).

Toplam fenolik madde tayini: Bitki özütlerindeki çözünebilen toplam fenolik madde içeriği Folin-Ciocalteu ayıracı kullanılarak belirlenmiştir. $0.25 \mathrm{~mL}$ ekstrak içeren $100 \mathrm{~mL}$ ' lik balon jojelerin içine $1.25 \mathrm{~mL}$ Folin-Ciocalteu ayıracı ve $2.5 \mathrm{~mL} \mathrm{NaHCO}_{3} \quad(\% 7.5)$ çözeltisi eklenerek $45^{\circ} \mathrm{C}$ 'de 45 dakika su banyosunda inkübe edilmiştir. İnkübasyon sonrası numuneler, aliminyum folyoya sarılıp 1 saat karanlık ortamda beklemeye bırakılmıştır. Karışımların absorbans1 720 nm'de spektrofotometrik olarak ölçülmüştür. Standart olarak gallik asitin kullanıldığı kalibrasyon grafiğine göre, toplam fenolik içerik gram başına $\mu \mathrm{g}$ gallik asit eşdeğerleri ( $\mu \mathrm{g} \mathrm{GAE/g)} \mathrm{olarak} \mathrm{ifade} \mathrm{edilmiştir} \mathrm{(Türkmen} \mathrm{vd.,}$ 2019).

Antioksidan aktivite tayini: Ekstratların serbest radikalleri giderme etkinliği olarak ifade edilen antioksidan aktiviteleri, DPPH (2,2- diphenyl 1-picrylhydrazyl) radikali kullanılarak belirlenmiştir. Ekstratlar, sırayla $20 \mu \mathrm{L}, 40 \mu \mathrm{L}$, $60 \mu \mathrm{L}, 80 \mu \mathrm{L}, 100 \mu \mathrm{L}$ olarak tüplere aktarılmış ve $3.9 \mathrm{~mL}$ metanol içerisinde hazırlanmış DPPH radikali $(0.025 \mathrm{~g} / \mathrm{L})$ $600 \mu \mathrm{L}$ olarak eklenmiştir. Tüpler vorteks cihazında karıştırılmış ve yaklaşık 30 dakika karanlık bir ortamda inkübasyona bırakılmıştır. İnkübasyon sonrası, spektrofotometrede $517 \mathrm{~nm}$ dalga boyunda tüplerin içerisindekilerin absorban değerleri okunmuştur. Kör için elde edilen absorbans değeri dikkate alınarak yapılan hesaplama ile yüzde inhibisyon değerleri belirlenmiştir (Brand-Williams vd., 1995). \% olarak belirlenen DPPH inhibisyonu aşağıdaki formüle göre hesaplanmıştır.

$\%$ İnhibisyon $=\left[\left(\mathrm{A}_{\text {kontrol }}-\mathrm{A}_{\text {örnek }}\right) / \mathrm{A}_{\text {kontrol }}\right] \times 100$

Antimikrobiyal aktivite tayini: İnsan ve g1da kaynaklı patojen mikroorganizmalara karşı goji meyve ekstratlarının antimikrobiyal aktiviteleri, disk difüzyon yöntemi kullanılarak, in vitro olarak, Klinik Laboratuvar Standartları Enstitüsü (CLSI, 2012) standartlarına göre belirlenmiştir. Disk difüzyon testi için; Elde edilen kuru ve / veya mumsu bitki ekstreleri dimetil sülfoksit (\%99.9;
DMSO) içerisinde çözülmüştür. $10^{6} \mathrm{KOB} / \mathrm{mL}$ bakteri hücresi $100 \mu \mathrm{L}$ olarak Mueller Hinton Agar (Merck) besiyerlerine ekimleri gerçekleştirilmiş, 15-20 dk kurumaya bırakılmıştır. Steril forseps kullanarak, 10,20 ve $30 \mu \mathrm{L}$ bitki ekstreleri içeren steril filtre kağıtları (6 mm çap) ve negatif kontrol (\% 10 DMSO) inoküle edilmiş agarlı besiyeri yüzeyine yerleştirilmiştir. Besiyerleri, bakteriler için 24 saat $37{ }^{\circ} \mathrm{C}^{\prime} \mathrm{de}$, maya ve küfler için 72 saat $25{ }^{\circ} \mathrm{C}^{\prime}$ de inkübasyona bırakılmıştır. İnkübasyondan sonra, inhibisyon bölgesini ifade eden zon çapı ölçümü (mm) yapılmıştır. Her bir inhibisyon bölgesi üç kez ölçülmüş, her bakteri ve maya-küf kültürü için antibakteriyel aktiviteye ve antifungal aktiviteye kıyasla üç kez bir ortalama değer elde edilmiştir.

İstatistiksel analizler: Örneklerin analiz sonuçları tesadüf blokları deneme planına göre Windows SPPS 20.0 software istatistik paket programı (SPSS Inc., Chiago, IL, USA) kullanılarak yorumlanmıştır. Araştırma sonuçları tek yönlü varyans analizi kullanılarak değerlendirilmiş ve önem farklılıkları Duncan çoklu karşılaştırma testine göre belirlenmiştir.

\section{BULGULAR}

Asetik asit-su ve etil alkol ile ekstrakte edilen goji meyvelerinin toplam fenolik madde miktarı ile antioksidan ve antimikrobiyal aktiviteleri belirlenmiştir. Çalışma sonuçlarına göre goji meyveleri ekstratlarından elde edilen toplam fenolik madde miktarları Tablo 1'de gösterilmiştir. Fenolik bileşikler, lipid serbest radikallerini etkisiz hale getirerek veya hidroperoksitlerin serbest radikallere ayrışmasını önleyerek antioksidan aktivite sergilerler. Folin-Ciocalteu yöntemi, toplam fenolik içeriği araştırmak için hılı ve yaygın olarak kullanılan bir analizdir, ancak farklı fenolik bileşiklerin Folin-Ciocalteu yönteminde farklı tepkileri olduğu bilinmektedir (Okan vd., 2013). Bu nedenle, bu çalışmada, toplam fenolik içerikleri, Tablo 1'de gösterildiği gibi, fenolik bileşiklerin $\mu \mathrm{g}$ gallik asit eşdeğeri (GAE) birimleri cinsinden hesaplanmıştır. Toplam fenolik madde miktarını belirlemede uygulanan Folin-Ciocalteu yöntemi sonucunda, Goji berry bitkisinin asetik asit-su çözgeniyle hazırlanan ekstraktının (5148 $\pm 49.49 \mu \mathrm{g}$ GAE/g), etanol çözgeniyle hazırlanan ekstraktına (3874 $\pm 9.89 \mu \mathrm{g}$ GAE/g) göre daha yüksek sonuç verdiği tespit edilmiştir. $\mathrm{Bu}$ çalışmada elde edilen toplam fenolik madde içeriğinin değerleri, Ionica vd., (2012) tarafindan sunulan $2.59 \pm 4.14 \mathrm{mg}$ GAE/g değerlerinden daha yüksek, Medine (2011) çalışmasında bildirilen goji meyveleri için 8,95 ila 10,36 mg GAE /g değerlerinden ve Kosar vd., (2003) rapor edilen $106.80 \pm 0.46 \mathrm{mg}$ GAE değerlerinden daha düşük olarak bulunmuştur.

Tablo 1. Goji berry (Lycium barbarum L.) ekstraklarının fenolik aktiviteleri.

\begin{tabular}{lc}
\hline Örnek & Toplam Fenolik Aktiviteleri $(\boldsymbol{\mu g ~ G A E} / \mathbf{g})$ \\
\hline G1E & $3874 \pm 9.89^{\mathrm{a}}$ \\
G1A & $5148 \pm 49.49^{\mathrm{b}}$ \\
a-b: , farkll harflerle gösterilen değerler istatistiksel olarak önemli farkllıklar göstermektedir $(\mathrm{p} \leq 0.05)$.
\end{tabular}


Goji meyve ektratlarının DPPH radikali giderme aktivitelerinin \% inhibisyon cinsinden hesaplanan antioksidan aktiviteleri Şekil 2'de gösterilmiştir. DPPH kararlı bir serbest radikaldir. DPPH ve ABTS +, numunenin elektron transfer reaksiyonları yoluyla radikal türlerin deaktivasyonundaki yeteneğini ölçen analizlerden biridir (Barontini vd., 2014). DPPH• 'in oluşturduğu reaksiyon karışımının gösterdiği absorban ne kadar düşük ise antioksidanın serbest radikal giderme aktivitesi o kadar yüksek olarak değerlendirilir (Ardağ, 2008).

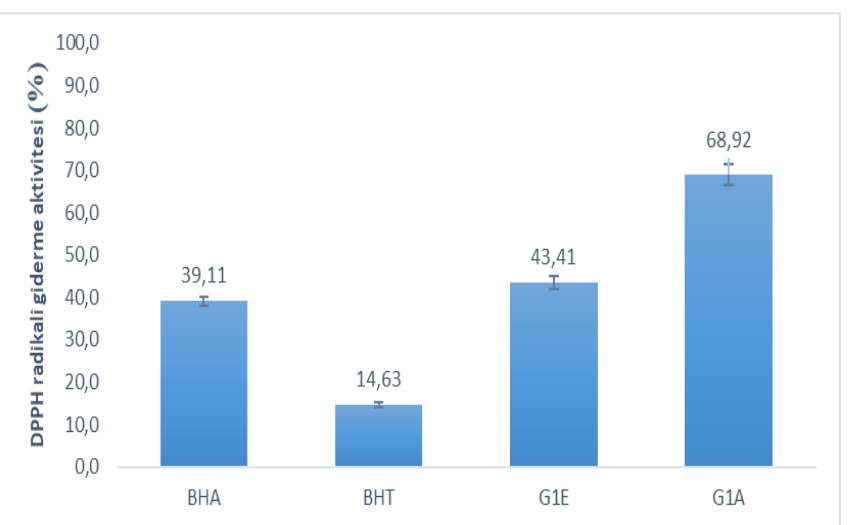

Şekil 2. Gojiberry meyvesinin asetik asit-su ekstraksiyonu (G1A) ve etanol ekstraksiyonu (G1E) DPPH radikali giderme aktiviteleri.

Şekil 2'de de görüldüğü üzere, goji berry bitkisinin meyve kısmında asetik asit-su karışımı ekstraksiyonunun, etanol ekstraksiyonuna göre daha iyi sonuç verdiği tespit edilmiştir. Bunun nedeni olarak, asetik asit-sudan oluşan çözeltinin etanole oranla daha yüksek miktarda antioksidan özellik gösteren maddeleri ekstrakte ettiği düşünülmektedir. Yapılan çalı̧̧malar, Goji meyvesinin kimyasal analizleri ile yüksek antioksidan aktivite gösterdiğini doğrulamıştır. Mevcut analizlere dayanarak $L$. barbarum'un serbest radikallere (süperoksit anyonu, hidroksil radikalleri) karşı temizleyici aktivite gösterdiği sonucuna varılmıştır. Goji antioksidan aktivitesi temel olarak karotenoid pigmentlere, flavonoidlere, polisakkarit fraksiyonuna ve vitamin analoguC-2-0- (beta-D-glikopiranosil) askorbik aside bağlanmaktadır (Guo vd., 2008; Jiang, 2014; Li ve Zhou, 2007; Lin vd., 2009; Wang vd., 2010; Zhang vd., 2011 a,b). Oksijen Radikal Emilim Kapasitesi (ORAC), beslenme antioksidan kapasitesini incelemek için bir yöntemdir ve bu yöntemde, bu kapasite, peroksit radikallerinin inhibisyon derecelerine göre değerlendirilir. Bununla birlikte, bu değerler organizmanın metabolizmasından ve absorpsiyon olaylarından bağımsızdır. Toplam-ORAC değerlerine göre meyvelerinin ortalama oksijen absorbsiyon kapasitesi açısından en yüksek değerden en düşük değere doğru siralama bögürtlen $>$ ahududu $>$ yabanmersini > çilek > goji meyvesi şeklindedir (Haytowitz ve Bhagwat, 2010). Araştırma sonuçlarına benzer olarak Zhang (2013) goji meyvesinin artan konsantrasyonlarla (10 $\mathrm{mg} / \mathrm{mL}, 20 \mathrm{mg} / \mathrm{mL}, 40 \mathrm{mg} / \mathrm{mL}, 50 \mathrm{mg} / \mathrm{mL}$ ) antioksidan kapasitesini sirasiyla \% 70.58,\% 65.21,\% 59.94 ve\% 52.99 olarak tespit etmiş̧ir.

Çalışmada asetik asit-su ve etanol ile ekstrakte edilen Goji berry'nin ( Lycium barbarum L.) meyvesinin insan ve gida patojeni olduğu bilinen bazı mikroorganizmalara karşı antimikrobiyal aktiviteleri saptanmıştır. Disk difüzyon yönteminin kullanıldığı çalışmada farklı konsantrasyonlarda $(10,20$ ve $30 \mu \mathrm{L})$ ekstraktların disklere ilave edilmesi sonrasında sürdürülen inkübasyon ile meydana gelen zon çapların ölçülmesiyle antimikobiyal etki tespit edilmiştir. Antimikrobiyel etkinin tespitinde kontrol grubu olarak, herhangi bir antimikrobiyal madde emdirilmemiş boş antimikrobiyel diskler kullanılmıştır. Ekstratların antimikrobiyal etkileri sonucu oluşan zon çapları Tablo 2'de gösterilmiştir.

Tablo 2. Goji berry (Lycium barbarum L.) ekstraklarının test mikroorganizmalarına karşı antimikrobiyal etkisi.

\begin{tabular}{|c|c|c|c|c|c|c|}
\hline \multirow[b]{4}{*}{ Mikroorganizmalar } & \multicolumn{6}{|c|}{ Ektraktlar } \\
\hline & \multicolumn{3}{|c|}{ G1A* $(\mu \mathrm{L})$} & \multicolumn{3}{|c|}{ G1E* $*(\mu \mathrm{L})$} \\
\hline & \multicolumn{6}{|c|}{ Zon çapları (mm) } \\
\hline & 10 & 20 & 30 & 10 & 20 & 30 \\
\hline Bacillus cereus & $\mathrm{NI}^{\mathrm{a}}$ & $\mathrm{NI}^{\mathrm{a}}$ & $\mathrm{NI}^{\mathrm{a}}$ & $\mathrm{NI}^{\mathrm{a}}$ & $\mathrm{NI}^{\mathrm{a}}$ & $\mathrm{NI}^{\mathrm{a}}$ \\
\hline Escherichia coli & $9,67 \pm 0,57^{\mathrm{a}}$ & $11,33 \pm 0,57^{\mathrm{b}}$ & $14,67 \pm 0,57^{\mathrm{c}}$ & $\mathrm{NI}^{\mathrm{a}}$ & $\mathrm{NI}^{\mathrm{a}}$ & $\mathrm{NI}^{\mathrm{a}}$ \\
\hline Staphylococcus aureus & $11,00 \pm 1,00^{\mathrm{a}}$ & $13,33 \pm 0,57^{\mathrm{b}}$ & $16,33 \pm 1,52^{\mathrm{c}}$ & $7,67 \pm 0,57^{\mathrm{a}}$ & $12,00 \pm 1,00^{\mathrm{b}}$ & $14,33 \pm 0,57^{\mathrm{c}}$ \\
\hline Staphylococcus epidermis & $\mathrm{NI}^{\mathrm{a}}$ & $\mathrm{NI}^{\mathrm{a}}$ & $\mathrm{NI}^{\mathrm{a}}$ & $\mathrm{NI}^{\mathrm{a}}$ & $\mathrm{NI}^{\mathrm{a}}$ & $\mathrm{NI}^{\mathrm{a}}$ \\
\hline Vibrio parahemolyticus & $\mathrm{NI}^{\mathrm{a}}$ & $\mathrm{NI}^{\mathrm{a}}$ & $\mathrm{NI}^{\mathrm{a}}$ & $8,67 \pm 0,57^{\mathrm{a}}$ & $10,67 \pm 0,57^{\mathrm{b}}$ & $13,00 \pm 1,00^{\mathrm{c}}$ \\
\hline Yersinia pseudotuberculosis & $\mathrm{NI}^{\mathrm{a}}$ & $\mathrm{NI}^{\mathrm{a}}$ & $\mathrm{NI}^{\mathrm{a}}$ & $\mathrm{NI}^{\mathrm{a}}$ & $\mathrm{NI}^{\mathrm{a}}$ & $9,00 \pm 1,73^{\mathrm{b}}$ \\
\hline Listeria monocytogenes & $9,33 \pm 0,57^{\mathrm{a}}$ & $11,67 \pm 0,57^{\mathrm{b}}$ & $15,00 \pm 1,00^{\mathrm{c}}$ & $8,67 \pm 0,57^{\mathrm{a}}$ & $10,67 \pm 0,57^{\mathrm{b}}$ & $15,67 \pm 0,57^{\mathrm{c}}$ \\
\hline Enterococcus faecalis & $\mathrm{NI}^{\mathrm{a}}$ & $10,67 \pm 1,15^{\mathrm{b}}$ & $13,67 \pm 0,57^{\mathrm{b}}$ & $\mathrm{NI}^{\mathrm{a}}$ & $10,67 \pm 0,57^{\mathrm{b}}$ & $13,67 \pm 0,57^{\mathrm{c}}$ \\
\hline Salmonella Typhimurium & $\mathrm{NI}^{\mathrm{a}}$ & $\mathrm{NI}^{\mathrm{a}}$ & $\mathrm{NI}^{\mathrm{a}}$ & $7,67 \pm 0,57^{\mathrm{a}}$ & $10,33 \pm 0,57^{\mathrm{b}}$ & $12,00 \pm 1,00^{\mathrm{c}}$ \\
\hline Klebsiella pneumoniae & $\mathrm{NI}^{\mathrm{a}}$ & $\mathrm{NI}^{\mathrm{a}}$ & $\mathrm{NI}^{\mathrm{a}}$ & $\mathrm{NI}^{\mathrm{a}}$ & $\mathrm{NI}^{\mathrm{a}}$ & $8,33 \pm 0,57^{\mathrm{b}}$ \\
\hline Proteus vulgaris & $\mathrm{NI}^{\mathrm{a}}$ & $\mathrm{NI}^{\mathrm{a}}$ & $\mathrm{NI}^{\mathrm{a}}$ & $\mathrm{NI}^{\mathrm{a}}$ & $\mathrm{NI}^{\mathrm{a}}$ & $\mathrm{NI}^{\mathrm{a}}$ \\
\hline Candida albicans & $\mathrm{NI}^{\mathrm{a}}$ & $8,67 \pm 0,57^{\mathrm{b}}$ & $11,33 \pm 0,57^{\mathfrak{c}}$ & $\mathrm{NI}^{\mathrm{a}}$ & $\mathrm{NI}^{\mathrm{a}}$ & $8,33 \pm 0,57^{\mathrm{b}}$ \\
\hline Aspergillus niger & $\mathrm{NI}^{\mathrm{a}}$ & $10,33 \pm 0,57^{\mathrm{b}}$ & $12,67 \pm 0,57^{\mathrm{c}}$ & $\mathrm{NI}^{\mathrm{a}}$ & $8,33 \pm 0,57^{\mathrm{b}}$ & $10,67 \pm 0,57^{\mathrm{c}}$ \\
\hline
\end{tabular}


Disk difüzyon yöntemine göre antimikrobiyal etkinin tespitinde, 5,5 - $9 \mathrm{~mm}$ inhibisyon çapı çok düşük inhibisyon, 9 - $12 \mathrm{~mm}$ inhibisyon çapı düşük inhibisyon, 12 $15 \mathrm{~mm}$ inhibisyon çap1 ortalama inhibisyon ve $15 \mathrm{~mm}$ ve üzeri yüksek inhibisyon olarak değerlendirilmektedir (Ulusoy vd., 2009). Tablo 2'de görüldüğü gibi, Goji berry ( $L$. barbarum) meyve kısmı ve asetik asit- su ile hazırlanan ekstratınının antimikrobiyal etkisinde, en yüksek inhibiyon etkisi Staphylococcus aureus'a karşı olduğu tespit edilmişken, Bacillus cereus, Staphylococcus epidermis, Vibrio parahemolyticus, Yersinia pseudotuberculosis, Salmonella Typhimurium, Klebsiella pneumoniae ve Proteus vulgaris'a karşı inhibisyon etki göstermemiştir. Candida albicans'a karşı düşük inhibisyon, Escherichia coli, Enterococcus faecalis ve Aspergillus niger' a karşı orta inhibisyon, Staphylococcus aureus ve Listeria monocytogenes'a karşı yüksek inhibisyon tespit edilmiştir. Goji berry (L. barbarum) meyve kismı ve etil alkol ile hazırlanan ekstratınının antimikrobiyal etkisi incelendiğinde ise, en yüksek inhibiyon etkisi Listeria monocytogenes'a karş1 olduğu tespit edilmişken, Bacillus cereus, Escherichia coli, Staphylococcus epidermis ve Proteus vulgaris'a karş1 inhibisyon etki göstermemiştir. Yersinia pseudotuberculosis, Klebsiella pneumoniae ve Candida albicans' a karşı çok düşük inhibisyon, Salmonella Typhimurium ve Aspergillus niger karşı düşük inhibisyon, Staphylococcus aureus, Vibrio parahemolyticus ve Enterococcus faecalis' a karşı orta inhibisyon, Listeria monocytogenes'a karşı yüksek inhibisyon tespit edilmiştir. Çalışma sonuçları Skenderidis vd., (2019) ile uyumlu olarak etanol ekstratlarının sulu ekstratlara göre daha yüksek antimikrobiyal aktivite gösterdiğini ortaya koymuştur. Diğer araştırma sonuçlarında goji meyvesinin antimikrobiyal etkisi Gram-negatif bakteriler üzerinde orta derecede bir antimikrobiyal etki göstermiş ve stafilokoklara karşı düşük bulunmuştur (Madeha Al-Seen, 2011).

\section{SONUÇ}

$\mathrm{Bu}$ çalışmada Goji berry ( $L$. barbarum) farklı çözücüler ile elde edilen ekstraktlarının biyoaktif özellikleri ve antimikrobiyal aktivitesi araştırılmıştır. Toplam fenolik madde miktarını belirlemede uygulanan Folin-Ciocalteu yöntemi sonucunda, Goji berry bitkisinin asetik asit-su çözgeniyle hazırlanan ekstraktının etanol çözgeniyle hazırlanan ekstraktına göre daha yüksek sonuç verdiği tespit edilmiştir. Antioksidan aktivitesinin belirlenmesi amacıyla yapılan DPPH medodu ile radikal giderme aktivitesi ölçülmüştür. Goji berry bitkisinin meyve kısmında asetik asit-su karışımı ekstraksiyonunun, etanol ekstraksiyonuna göre daha iyi sonuç verdiği tespit edilmiştir. Antimikrobiyal aktivite için yapılan disk difüzyon yöntemiyle petrilerde görülen zon çapları ölçülerek 13 mikroorganizma üzerinde analizler yapılmıştır. Analizler sonucu, disklere ilave edilen ekstrakt konsantrasyonu artışı ile antimikrobiyal etkiyi gösteren zon çaplarında da artış görülmüştür. Ekstraktların antimikrobiyal özellikleri değerlendirildiğinde test mikroorganizmalarından Staphylococcus aureus ve Listeria monocytogenes' e karşı güçlü bir antimikrobiyal etkiye sahip oldukları tespit edilmiştir. Ayrıca, ektraktların zayıf da olsa antifungal aktiviteye sahip oldukları bulunmuştur.

\section{KAYNAKLAR}

Al-Seeni, M.N. (2011). Goji extract as antibacterial agent and antioxidant on Roridin $E$ induced hepatotoxicity in male rat. Journal of International Environmental Application and Science, 6(1), 136-140.

Amagase, H. \& Nance, D.M. (2008). A randomized, doubleblind, placebocontrolled, clinical study of the general effects of a standardized Lycium barbarum (goji) juice, GoChi. Journal of Alternative and Complementary Medicine, 14, 403-412.

Amagase, H., \& Farnsworth, N.R. (2011). A review of botanical characteristics, phytochemistry, clinical relevance in efficacy and safety of Lycium barbarum fruit (Goji). Food Research International, 44(7), 1702-1717.

Ardă̆, A. (2008). Antioksidan kapasite tayin yöntemlerinin analitik açıdan karşılaştırılması. Yüksek lisans tezi, Adnan Menderes Üniversitesi, Fen Bilimleri Enstitüsü, Aydın, Türkiye, 70s).

Barontini, M., Bernini, R., Carastro, I., Gentili, P. \& Romani, A. (2014). Synthesis and DPPH radical scavenging activity of novel compounds obtained from tyrosol and cinnamic acid derivatives. New Journal of Chemistry, 38, 809-816.

Brand-Williams, W., Cavalier, M. E. \& Berset, C. (1995). Use of free radical method to evaluate antioxidant activity. Food Science and Technology, 28(1), 2530.

Carvalho, A.P., Mendes, M., Moreira, M.M., Cruz, D., Magalhães, J.M., Barroso, M.F. \& Matos, C.D. (2016). Microwave-assisted extraction in goji berries: effect on composition and bioactivity, evaluated through conventional and nonconventional methodologies. International Journal of Food Science \& Technology, 51(6), 1401-1408.

Chang, R.C. \& So, K.F. (2008). Use of anti-aging herbal medicine, Lycium barbarum, against agingassociated diseases. What do we know so far. Cellular and Molecular Neurobiology, 28(5), 64352.

Chao, J.C., Chiang, S.W., Wang, C.C., Tsai, Y.H. \& Wu, M.S. (2006). Hot waterextracted Lycium barbarum and Rehmannia glutinosa inhibit proliferation and induce apoptosis of hepatocellular carcinoma cells. 
World Journal of Gastroenterology, 12(28), 44784484.

CLSI. (2012). Performance Standards for Antimicrobial Susceptebility Testing. Twenty-second Informational Supplement. Clinical and Laboratory Standards Insitute, Wayne, PA, USA, M100-S22. 59p

Engin, M.S., Kalkan, S., Çay, S., Güder, A., Otă̆, M.R., Gür, G. \& Kablan, A. (2018). DPPH Radical Scavenging, Phenolic and Antimicrobial Activity of Momordica charantia and Rheum ribes. Research Journal of Pharmaceutical, Biological and Chemical Sciences, 9(4), 447-458.

Gan, L., Zhang, S.H., Yang, X. L. \& Xu, H.B. (2004). Immunomodulation and antitumor activity by a polysaccharide-protein complex from Lycium barbarum. International Immunopharmacology, 4, 563-569.

Gong, X. \& Rubin, L.P. (2015). Role of macular xanthophylls in prevention of common neovascular retinopathies: Retinopathy of prematurity and diabetic retinopathy. Archives of Biochemistry and Biophysics, 572, 40-48.

Guo, D.J., Cheng, H.L., Chan, S.W. \& Yu, P.H.F. (2008). Antioxidative activities and the total phenolic contents of tonic Chinese medicinal herbs. Inflammopharmacology, 16, 201-207.

Haytowitz, D.B. \& Bhagwat, S. (2010). Database for the oxygen radical absorbance capacity (ORAC) of selected foods, Release 2. Washington (DC): US Department of Agriculture;

Hsu, H.Y., Yang, J.J., Ho, Y.H. \& Lin, C.C. (1999). Difference in the effects of radioprotection between aerial and root parts of Lycium chinense. Journal of Ethnopharmacology, 64(2), 101-108.

Huang, Y., Lu, J. \& Shen, Y. (1999). The protective effects of total flavonoids from Lycium Barbarum $L$. on lipid peroxidation of liver mitochondria and red blood cell in rats. Wei sheng yan jiu= Journal of hygiene research, 28(2), 115-116.

Ionica, E.M., Nour, V. \& Trandafir, I. (2012). Polyphenols content and antioxidant capacity of goji fruits (Lycium chinense). South Western Journal of Horticulture, Biology and Environment, 3(2), 121129.

Jiang, L. (2014). Preparation and antioxidant activity of Lycium barbarum oligosaccharides. Carbohydrate Polymers, 99, 646-648.

Kulczyński, B. \& Gramza-Michałowska, A. (2016). Goji berry (Lycium barbarum): composition and health effects-a review. Polish Journal of Food and Nutrition Sciences, 66(2), 67-76.

Kosar, M., Altintas, A., Kirimer, N. \& Baser, K.H.C. (2003). Determination of the free radicals scavenging activity of Lycium extracts. Chemistry of Natural Compounds, 39, 439-442.
Li, X., \& Zhou, A. (2007). Evaluation of the antioxidant effects of polysaccharides extracted from Lycium barbarum. Medicinal Chemistry Research, 15, 471482.

Lin, C., Wang, C. \& Chang, S. (2009). Antioxidative activity of polysaccharide fractions isolated from Lycium barbarum Linnaeus. International Journal of Biological Macromolecules, 45, 146-151.

Manikandan, R., Thiagarajan, R., Goutham, G., Arumugam, M., Beulaja, M. \& Nabavi, S.M. (2016). Zeaxanthin and ocular health, from bench to bedside. Fitoterapia, 109, 58-66.

Medina, M.B. (2011). Determination of the total phenolics in juices and superfruits by a novel chemical method. Journal of Functional Foods, 3, 79-87.

Noshada, M., Hojjatia, M. \& Behbahani, B.A. (2018). Black Zira essential oil: Chemical compositions and antimicrobial activity against the growth of some pathogenic strain causing infection. Microbial Pathogenesis, 116, 153-157.

Okan, O.T., Varlıbaş, H., Öz, M. \& Deniz İ. (2013). Antioksidan analiz yöntemleri ve doğu Karadeniz bölgesinde antioksidan kaynağı olarak kullanılabilecek odun dışı bazı bitkisel ürünler. Kastamonu Üniversitesi Orman Fakültesi Dergisi, 13(1), 48-59.

Peng, Y., Ma, C., Li, Y., Leung, K.S.Y., Jiang, Z.H. \& Zhao, Z. (2005). Quantification of zeaxanthin dipalmitate and total carotenoids in Lycium fruits (Fructus Lycii). Plant Foods for Human Nutrition, 60, 161-164.

Potterat, O. (2010). Phytochemistry, pharmacology and safety in the perspective of traditional uses and recent popularity. Planta Medica, 76, 7-19.

Qian, J.Y., Liu, D. \& Huang, A.G. (2004). The efficiency of flavonoids in polar extracts of Lycium chinense Mill. fruits as free radical scavenger. Food Chemistry, 87(2), 283-288.

Skenderidis, P., Mitsagga, C., Giavasis, I., Petrotos, K., Lampakis, D., Leontopoulos, S., Hadjichristodulou, C. \& Tsakalof, A. (2019). The in vitro antimicrobial activity assessment of ultrasound assisted Lycium barbarum fruit extracts and pomegranate fruit peels. Journal of Food Measurement and Characterization, 13(3), 20172031.

Sze, S.C.W., Song, J.X., Wong, R.N.S., Feng, Y.B., Ng, T.B., Tong, Y. \& Zhang, K.Y.B. (2008). Application of SCAR (sequence characterized amplified region) analysis to authenticate Lycium barbarum (wolfberry) and its adulterants. Biotechnology and Applied Biochemistry, 51(1), 1521.

Türkmen, F.U., Mercimek Takcı, H.A., Sarıü̈llü Önalan, F.E. \& Sağlam, H. (2019). Arum dioscoridis ekstraktlarının toplam fenolik, flavonoid içerikleri 
ile antioksidan ve antibakteriyel aktivitelerinin araştırılması. Harran Üniversitesi Mühendislik Dergisi, 4(1), 102-108.

Ulusoy, E., Kolayli, S. \& Sarikaya, A.O. (2010). Antioxidant and antimicrobial activity of different floral origin honeys from Turkiye. Journal of Food Biochemistry, 34, 321-335.

Wang C.C., Chang S.C., Inbaraj B.S. \& Chen B.H. (2010). Isolation of carotenoids, flavonoids and polysaccharides from Lycium barbarum L. and evaluation of antioxidant activity. Food Chemistry, 120, 184-192.

Yin, G. \& Dang, Y. (2008). Optimization of extraction technology of the Lycium barbarum polysaccharides by Box-Behnken statistical design. Carbohydrate Polymers, 74(3), 603-610.

Yu, M.S., Leung, S.K., Lai, S.W., Che, C.M., Zee, S.Y., So, K.F., Yuen, WH. \& Chang, R.C.C. (2005). Neuroprotective effects of anti-aging oriental medicine Lycium barbarum against beta-amyloid peptide neurotoxicity. Experimental Gerontology, 40(8), 716-727.

Zhang, Z., Liu, X., Wu, T., Liu, J., Zhang, X., Yang, X., Goodhert, M.J. Engelhardt, J.F. \& Wang, Y. (2011). Selective suppression of cervical cancer Hela cells by $2-O-\beta$-Dglucopyranosyl- L-ascorbic acid isolated from the fruit of Lycium barbarum $\mathrm{L}$. Cell Biology and Toxicology, 27(2), 107-121.
Zhang, Z., Liu, X., Zhang, X., Liu, J., Hao, Y., Yang, X. \& Wang, Y. (2011). Comparative evaluation of the antioxidant effects of the natural vitamin $\mathrm{C}$ analog 2-O- $\beta$-D-glucopyranosyl-L-ascorbic acid isolated from Goji berry fruit. Archives of Pharmacal Research, 34(5), 801-810.

Zhang, J. (2013). Antioxidant Properties of Goji Berries. Wayne State University Theses. 250p.

Zhang, K.Y., Leung, H.W., Yeung, H.W. and Wong, R. N. (2001). Differentiation of Lycium barbarum from its related Lycium species using random amplified polymorphic DNA. Planta Medica, 67(4), 379-381.

\section{*Corresponding author's:}

Dr. Selin KALKAN

Giresun Üniversitesi, Mühendislik Fakültesi, Gıda Mühendisliği Bölümü, Giresun, Türkiye.

\E-mail: selin.kalkan@giresun.edu.tr

ORCID : https://orcid.org/0000-0002-4142-3152

GSM : $+90(532) 5457026$

Telefon : +90 (454) 3104174

Faks : : $+90(454) 3101745$ 